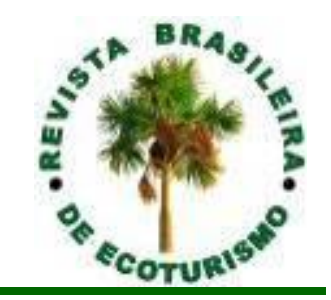

\title{
Avaliando zonas de amortecimento de Unidades de Conservação em áreas urbanizadas: o caso do município de Sorocaba (SP)
}

\section{Evaluating buffer zones of Protected Areas in urbanized areas: the case of the municipality of Sorocaba (SP, Brazil)}

\author{
Kaline de Mello, Marina Pannunzio Ribeiro, Roberta Averna Valente
}

\begin{abstract}
RESUMO: A discussão e projetos de desenvolvimento de zonas de amortecimento (ZA) no entorno de áreas protegidas urbanas é considerado um grande desafio. A delimitação da ZA deve levar em consideração critérios técnico-científicos, tais como, de uso e ocupação da terra, critérios hidrográficos, critérios ambientais e sociais, para que dessa forma possa se estabelecer um ambiente urbano ecologicamente sustentáveis e que traga resiliência para a biodiversidade, garantindo equidade no provimento de serviços ecossistêmicos para a toda a população urbana. Sendo assim, este estudo objetivou avaliar a estrutura da paisagem nos entornos das áreas protegidas urbanas, utilizando técnicas de geoprocessamento e Ecologia de Paisagem, visando fornecer subsídios à proposição de uma ZA comum às áreas protegidas urbanas do município de Sorocaba. A distância euclidiana média entre as Unidades de Conservação (UCs) de Sorocaba é de 4.782,24 m, e o Parque Natural Municipal de Corredores da Biodiversidade é o mais distante de outras UCs. A Estação Ecológica Bráulio Guedes da Silva, é a menor UC do município ( 8,9 ha) é a única que não tem o suporte de um remanescente fora dos limites protegidos. $A$ área mapeada é composta majoritariamente pelo uso antrópico da terra, que corresponde a mais de $78 \%$ do uso da terra, sendo a maior parte ocupada por áreas urbanas e campos antrópicos de vegetação pioneira. A cobertura florestal nativa, está distribuída entre 706 remanescentes, sendo que $84,14 \%$ não possuem mais que dez (10) hectares. Apesar de pequenos, os remanescentes estão próximos entre si (NEAR $<50 \mathrm{~m})$, favorecendo dessa forma a conectividade, conquistada através de trampolins ecológicos. Os campos antrópicos de vegetação pioneira apontados na área de estudo podem servir a projetos de restauração florestal, desempenhando um papel importante na mitigação dos impactos da fragmentação florestal, melhorando a estrutura florestal e a conectividade da paisagem, promovendo a conexão entre as áreas protegidas urbanas e outros fragmentos florestais.
\end{abstract}

PALAVRAS-CHAVE: Zona de Amortecimento; Planejamento Urbano; Redes Ecológicas Urbanas; Reflorestamento; Geoprocessamento. 
ABSTRACT: The discussion and projects of buffer zones (ZA) surrounding urban protected areas are significant challenges. Design the limits of the ZA must consider technical-scientific criteria, such as land-use/land-cover, river network, environmental, and social aspects. It can promote an ecologically sustainable urban environment that brings resilience to biodiversity, ensuring equity in providing ecosystem services to the entire urban population. Thus, this study aimed to evaluate the landscape structure around urban protected areas, using geoprocessing technique and Landscape Ecology, supplying subsidy for the proposition of a common ZA to urban protected areas in the municipality of Sorocaba. The average Euclidean distance between the PAs of Sorocaba is 4,782.24 $\mathrm{m}$. The Municipal Natural Park of "Corredores da Biodiversidade" is the most isolated area from other PAs. The "Bráulio Guedes da Silva" Ecological Station is the smallest PA in the municipality ( 8.9 ha). It is the only one that does not support a forest remnant surrounding the protected limits. The mapped area mainly comprises anthropic land-use, which corresponds to more than $78 \%$ of land use. The majority being occupied by urban areas and anthropic fields with pioneer vegetation. The native forest cover is distributed among 706 remnants, with $84.14 \%$ having no more than ten (10) hectares. These small remnants are close to each other (NEAR $<50 \mathrm{~m}$ ), thus favoring connectivity achieved through ecological springboards. The anthropic fields of pioneer vegetation identified in the study can serve forest restoration projects, playing an essential role in mitigating forest fragmentation. These lands can improve forest structure and landscape connectivity, promote the connection between PAs and other forest fragments on the landscape.

KEYWORDS: Buffer Zone; Urban Planning; Urban Ecological Network; Restoration; GIS.

\section{Introdução}

As Unidades de Conservação (UCs) são internacionalmente conhecidas como Áreas Protegidas e são criadas para minimizar as perdas de biodiversidade no mundo todo (IUCN, 2019a). Esses espaços protegidos garantem a conservação das espécies e fornecem serviços ecossistêmicos fundamentais como conservação de solo e água (LAURANCE et al., 2012).

As preocupações crescentes com os impactos das pressões antrópicas sobre a biodiversidade levaram a um aumento no número e na extensão das áreas protegidas nos trópicos (JENKINS; JOPPA, 2009; IUCN, 2019a). No Brasil, atualmente, $30 \%$ da cobertura total de vegetação de Mata Atlântica está localizada dentro de áreas protegidas (REZENDE et al., 2018).

O Bioma Mata Atlântica é um hotspot mundial de biodiversidade, muito ameaçado pela expansão urbana devido sua proximidade com umas das áreas mais adensadas da América Latina (São Paulo e Rio de Janeiro, por exemplo) (JOLY; METZGER; TABARELLI, 2014). A rápida expansão urbana ocorrida no Bioma gerou a supressão ou diminuição de áreas dos fragmentos florestais (FAHRIG, 1997; HANSKI, 2011), alterações na permeabilidade da matriz aos fluxos biológicos (METZGER, 2006) e, ainda, o aumento de efeitos de barreira, dificultando a dispersão de espécies (HANSEN; DEFRIES, 2007; LAURANCE et al., 2012).

Além da perda da biodiversidade, a perda das áreas florestais afeta o provimento dos serviços ecossistêmicos que são fundamentais para o bem-estar e saúde humana (DÍAZ et al., 2006; PICHARILLO; RANIERI, 2019). Tanto a quantidade quanto a qualidade desses serviços são diretamente dependentes 
da diversidade de espécies, genes e ecossistemas, dependentes portanto da biodiversidade local, regional ou global (TEEB, 2010).

Buscando atender agendas de proteção da biodiversidade e a manutenção dos serviços ecossistêmicos, em 2014 o município de Sorocaba lança o Plano Municipal da Mata Atlântica (SOROCABA, 2014) e inicia um processo de governança sobre algumas áreas com características ambientais relevantes. Atualmente o município possui cinco UCs criadas e geridas na esfera municipal e reguladas pela Lei $\mathrm{n}$. 9.985/2000, que estabeleceu o Sistema Nacional de Unidades de Conservação (SNUC) (BRASIL, 2000).

O município que é o maior aglomerado urbano da região metropolitana de Sorocaba (EMPLASA, 2018), possui $99 \%$ da sua população vivendo em áreas urbanas (IBGE, 2020) e 37,36\% da paisagem coberta por estruturas impermeáveis, tais como, asfalto, concreto, infraestruturas urbanas e construções de baixo a alto porte (RIBEIRO; MELLO; VALENTE, 2021). Assim, as cinco UCs criadas no município de Sorocaba podem ser chamadas de áreas protegidas urbanas, por estarem situadas dentro ou no limite de um grande centro populacional.

As áreas protegidas urbanas são distintas de UCs por serem espaços protegidos porém constantemente ameaçados pela expansão urbana e intensificação do desenvolvimento urbano; são afetados de forma desproporcional pelo crime, vandalismo, despejo de lixo e poluição luminosa e sonora; e estão sujeitos a efeitos de borda urbana como incêndios, poluição do ar e da água e a introdução de espécies exóticas invasoras (TRZYNA, 2014). Nesse sentido, um dos aspectos mais importantes a considerar para as áreas protegidas urbanas diz respeito à dificuldade de definição ou à ausência de uma zona de amortecimento $(Z A)$.

As ZA são áreas em torno das UCs, dentro das quais as atividades humanas estão sujeitas a regras e restrições específicas (SAYER, 1991). As ZA são muito importantes visto que os esforços de conservação baseados somente em UCs podem não ser capazes de manter os processos ecológicos, que se estendem além das reservas naturais (HILTY et al., 2020; LAURANCE et al., 2012). Assim, surge a necessidade de conservar ou restaurar os habitats críticos fora das UCs para manter a conectividade funcional das redes de habitats da paisagem (OPDAM; STEINGRÖVER; ROOIJ, 2006; SANTINI; SAURA; RONDININI, 2016; SAURA et al., 2018).

Além disso, as ZA e a redes de conectividade entre as áreas protegidas urbanas trazem, além dos benefícios de aumento de áreas verdes e o impacto na diversidade vegetal e animal, a equidade socioambiental, servindo como estruturas de transformação social e ambiental nas cidades, de maneira a beneficiar os seres humanos, incluindo grupos sociais desfavorecidos, sem acesso a áreas verdes (LOVELL; TAYLOR, 2013). As trilhas ambientais urbanas, ligando as UCs, funcionam não só como conectores físicos, mas também psicológicos para os habitantes das cidades, trazendo o pertencimento ao espaço público (UN; WHO, 2020), além de melhorias da saúde física e mental e melhores experiências ao ar livre (SHANAHAN et al., 2015; UN; WHO, 2020).

No entanto, a aplicação de ZA em paisagens altamente urbanizadas como a do município de Sorocaba é um grande desafio, visto que casas, lojas e até 
fábricas e prédios de apartamentos foram construídos até os limites das áreas protegidas. Onde existem oportunidades para criar uma ZA, é necessário regulamentar o uso de terras de propriedade privada, comprar ou comercializar essas terras, ou restringir o desenvolvimento em terras já controladas por um órgão público (TRZYNA, 2014).

Assim, a avaliação quantitativa do território nas regiões periféricas das UCs do município de Sorocaba, representa uma ferramenta importante para o planejamento e gestão da paisagem urbana, gerando informações essenciais que podem subsidiar a proposição da delimitação da ZA no ambiente urbano. A compreensão da estrutura da paisagem em áreas urbanas é necessária para dar suporte ao planejamento urbano, subsidiando técnica e cientificamente a implementação de políticas públicas (MELLO; TOPPA; CARDOSO-LEITE, 2016; SMITH et al., 2018).

As técnicas de geoprocessamento e princípios ecológicos da paisagem são cada vez mais aplicada ao planejamento e gestão urbana (FARINA, 2006). Assim, aliando técnicas de geoprocessamento e Ecologia de Paisagem a estrutura de uma paisagem pode ser interpretada por meio de avaliações dos padrões de uso e cobertura da terra, obtidos por meio de imagens de satélites, técnicas de geoprocessamento e métricas de paisagem (MCGARIGAL, 2015).

Neste contexto, este estudo objetivou avaliar a estrutura da paisagem nos entornos das áreas protegidas urbanas, utilizando técnicas de geoprocessamento e Ecologia de Paisagem, visando fornecer subsídios à proposição de uma ZA comum às áreas protegidas urbanas do município de Sorocaba. Os objetivos específicos são: (1) cálculo das distâncias entre as UCs; (2) avaliação da estrutura da paisagem e dos fragmentos florestais; (3) identificar áreas de campos antrópicos de vegetação pioneira que possam ser restabelecidas como áreas de interesse ambiental entre as UCs, propondo dessa forma estratégias de manejo da paisagem urbana que proporcionem ambientes ecologicamente sustentáveis e tragam resiliência para a biodiversidade, garantindo provimento de serviços ecossistêmicos para a população da cidade.

\section{Material e Métodos}

\section{Caracterização da área de estudo}

A área de estudo abriga cinco UCs de proteção integral (Figura 1). As UCs de proteção integral são bastante restritivas e têm como objetivo principal a manutenção dos ecossistemas naturais, permitindo apenas o uso indireto dos recursos naturais, como turismo ecológico (BRASIL, 2000). sendo elas:

As cinco de UCs de proteção integral foram criadas entre 2011 e 2016,

- Parque Natural Municipal de Corredores da Biodiversidade, foi criado em 2011 e conta com área de 62,5 ha (SOROCABA, 2011);

- Parque Natural Municipal de Brigadeiro Tobias, foi criado em 2015 em uma área de 11,7 ha (SOROCABA, 2015a); 
- Estação Ecológica Municipal do Pirajibu foi criada em 2015 em uma área de 45 ha (SOROCABA, 2015b);

- Estação Ecológica Governador Mário Covas foi criada em 2015 em uma área de 50 ha (SOROCABA, 2015c); e

- Estação Ecológica Bráulio Guedes da Silva foi criada em 2016 em uma área de 8,9 ha (SOROCABA, 2016).

Dentre as UCs municipais, apenas o Parque Natural Municipal de Corredores da Biodiversidade conta com ZA definida no Plano de Manejo em 2012 (SOROCABA, 2012).

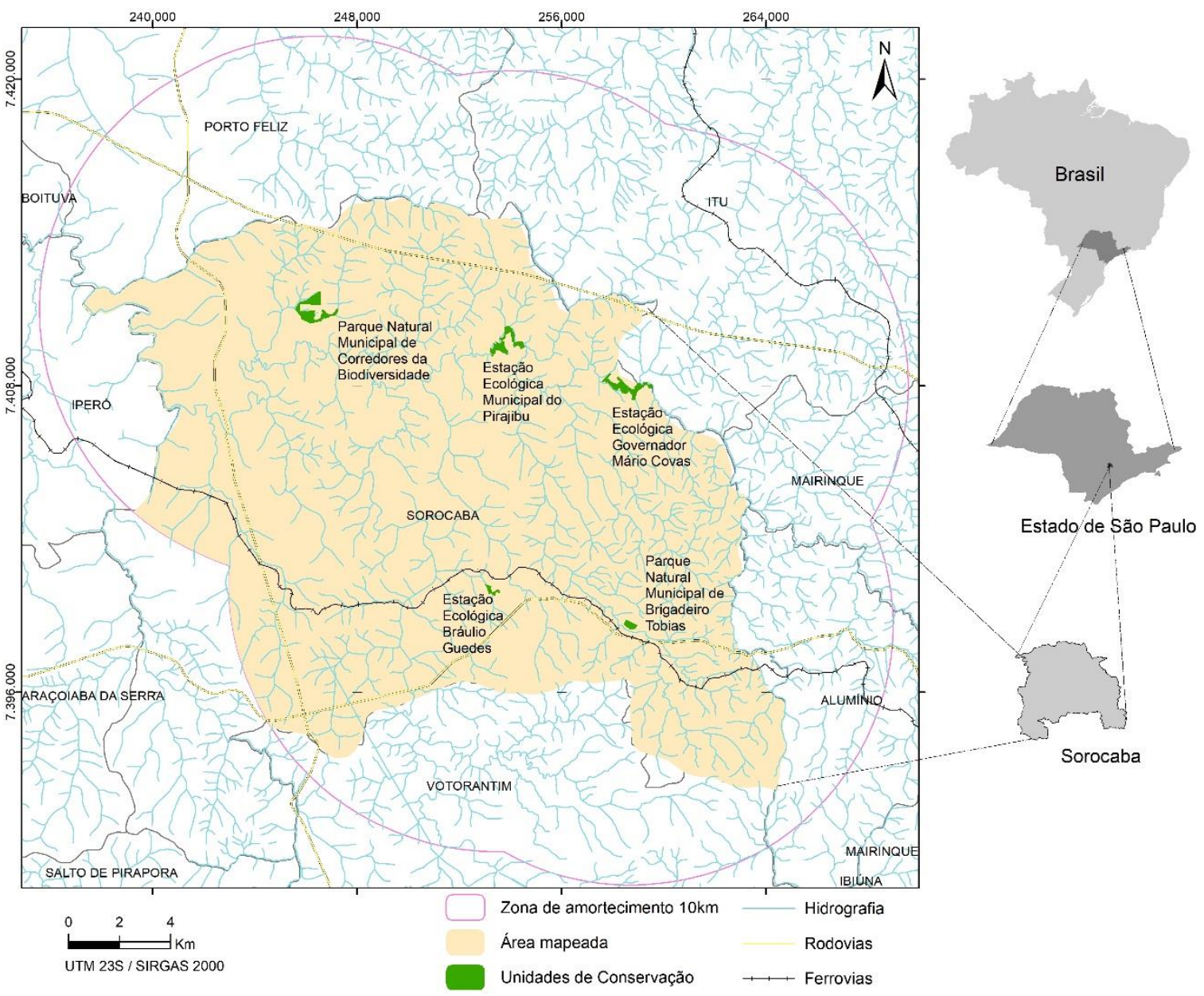

Figura 1:Limite do mapeamento e a localização das cinco Unidades de Conservação do município de Sorocaba, estado de São Paulo, Brasil.

Figure 1: Limit of mapped and location of the five Protected Areas in the city of Sorocaba, state of São Paulo, Brazil.

Fonte: CETESB (1977); CNUC (2012); DNIT (2013), adaptado pelas autoras (2021).

Source: CETESB (1977); CNUC (2012); DNIT (2013), adapted by the author (2021).

\section{Mapeamento do uso e cobertura das terras}

No Brasil, a Lei Federal no 9.985 (18 de julho de 2000) que estabeleceu o SNUC, prevê a criação de zonas de amortecimento, contudo "[...] os limites da zona de amortecimento e dos corredores ecológicos e as normas [...] poderão ser definidas no ato de criação da unidade ou posteriormente". 
Assim, neste estudo foi inicialmente adotado como limite da área de estudo a região de dez (10) quilômetros de distância a partir dos limites das UCs municipais (Figura 1), conforme o Decreto Federal no 99.274/1990 e a Resolução CONAMA n 013/1990, que estabeleceram "áreas circundantes" às Unidades de Conservação, definindo que, em um raio de dez quilômetros, o licenciamento de qualquer atividade que pudesse afetar a biota deveria ser obrigatoriamente realizado pelo órgão ambiental competente, mediante autorização do órgão gestor da UC.

Contudo, ao estipular um raio de dez quilômetros a partir dos limites das UCs municipais, as áreas ultrapassam os limites municipais. Nesse sentido, sendo as UCs geridas na esfera municipal, diminui-se as "áreas circundantes" do entorno das UCs, estabelecendo os limites municipais como limites das áreas que foram mapeadas, estabelecendo dessa forma a área mapeada total de 38.624,28 ha (Figura 1).

O mapeamento de uso e cobertura das terras utilizado nesse estudo possui exatidão global de $93,23 \%$ e foi produzido por Ribeiro; Mello e Valente (2020), pelo método de classificação supervisionada de máxima verossimilhança (MAXVER).

Para tanto, foram utilizadas imagens do satélite CBERS-4 (resolução espacial de 10m; bandas espectrais: verde, vermelho e infravermelho próximo, ano de 2016) fornecidas gratuitamente pelo INPE (http://www.inpe.br/). Utilizouse, ainda, os limites municipais do IBGE (2019), a rede hidrográfica foi obtida junto a Companhia Ambiental do Estado de São Paulo (Cetesb http://cetesb.sp.gov.br), e as malhas viária e ferroviária junto ao Departamento Nacional de Infraestrutura de Transportes (DNIT - http://dnit.gov.br). Todos os mapas estavam na escala 1:50.000 e disponíveis gratuitamente. Os limites das UCs foram adquiridos gratuitamente no site do Cadastro Nacional de Unidades de Conservação (CNUC - https://www.mma.gov.br/areas-protegidas/cadastronacional-de-ucs) na escala de 1:50.000.

Segundo Ribeiro; Mello e Valente (2020), as classes de uso e cobertura da terra são definidas como, (1) área florestal, identificada como Floresta Estacional Semidecidual do Bioma Mata Atlântica e formações florestais de Cerrado; (2) Silvicultura, sendo áreas ocupadas com plantios de Eucalyptus sp. ou Pinus sp.; (3) Culturas agrícolas temporárias, cultivo de plantas de curta ou média duração, com ciclo vegetativo inferior a um ano, como milho, alface, pimentão, mandioca, entre outras; (4) Campos antrópicos de vegetação pioneira, correspondem a campos antrópicos com predomínio de plantas de pequeno porte; (5) Culturas agrícolas permanentes, são as áreas ocupadas com plantios de culturas perenes, como frutíferas e café; (6) Várzea / Zonas ripárias, vegetação rasteira em áreas úmidas e próximas a corpos d'água; (7) áreas urbanas, são áreas ocupadas com construções, os bairros rurais, os condomínios mais afastados dos principais centros urbanos, solos desnudos próximos a áreas urbanas e outros tipos de ocupação da terra onde existe a predominância de construções; (9) áreas de mineração, são as áreas exploradas pela extração de minerais metálicos e minerais não metálicos e (10) corpos d'água, formados por lagos e reservatório. 


\section{Distância entre UCs}

A distância euclidiana, ou borda-a-borda, entre UCs foi calculado pela Equação 1 (MCGARIGAL, 2015):

$\mathrm{NEAR}=\mathrm{h}_{\mathrm{ij}}$

(Equação 1)

Sendo:

$h_{i j}=$ distância $(m)$ do vizinho mais próximo.

Unidade: metros $(\mathrm{m})$.

Limite: NEAR > 0, sem limite.

\section{Estrutura da paisagem e dos fragmentos florestais}

A classe área florestal foi extraída do mapa de uso e cobertura da terra e caracterizada por meio das métricas tradicionais de Ecologia de Paisagem, desenvolvidas por McGarigal (2015) em ambiente SIG. A categorização aconteceu: a) em nível de classe, por meio das métricas: índices de tamanho dos fragmentos e índices de proximidade, incluindo os respectivos valores de desvio padrão e coeficientes de variação; e b) em nível de fragmentos, por meio das métricas: índice de área (AREA) e índice de proximidade (NEAR) (MCGARIGAL, 2015), conforme descrito no Tabela 1.

Tabela 1: Métricas de paisagem em níveis de fragmento e de classe de uso e cobertura da terra utilizadas para caracterizar a estrutura da paisagem da área de estudo.

Table 1: Landscape metrics in fragment levels, land use/land cover class employed to the landscape structure characterization of the study area.

\begin{tabular}{|c|c|c|}
\hline \multirow{7}{*}{$\begin{array}{l}\text { Índices de } \\
\text { classe }\end{array}$} & \multirow{4}{*}{$\begin{array}{l}\text { Índice de } \\
\text { tamanho }\end{array}$} & Número de fragmentos \\
\hline & & Tamanho médio dos fragmentos \\
\hline & & Desvio padrão do tamanho médio de fragmentos \\
\hline & & Coeficiente de variação do tamanho médio de fragmentos \\
\hline & \multirow{3}{*}{$\begin{array}{l}\text { Índice de } \\
\text { proximidade }\end{array}$} & Distância média entre fragmentos \\
\hline & & Desvio padrão para a distância média entre fragmentos \\
\hline & & Coeficiente de variação para a distância média entre fragmentos \\
\hline \multirow{2}{*}{$\begin{array}{l}\text { Índices de } \\
\text { fragmentos }\end{array}$} & Índice de área & Área do fragmento (AREA) \\
\hline & $\begin{array}{l}\text { Índice de } \\
\text { proximidade }\end{array}$ & $\begin{array}{l}\text { Distância média euclidiana, ou borda-a-borda entre fragmentos } \\
\text { (NEAR) }\end{array}$ \\
\hline
\end{tabular}

Fonte: McGarigal (2015), adaptado pelas autoras (2021)

Source: McGarigal (2015), adapted by the author (2021).

\section{Resultados e Discussão}

As UCs de Sorocaba localizam-se majoritariamente próximas a cursos d'água e apresentam distância média (distância euclidiana) entre elas de 4.782,24 m (Figura 2). As UCs mais próximas são a Estação Ecológica Municipal do Pirajibu e a Estação Ecológica Governador Mário Covas, com 3.258,78 m entre elas. A UC mais isolada é o Parque Natural Municipal de Corredores da Biodiversidade que dista 6.122,56 m da Estação Ecológica Municipal do Pirajibu. 


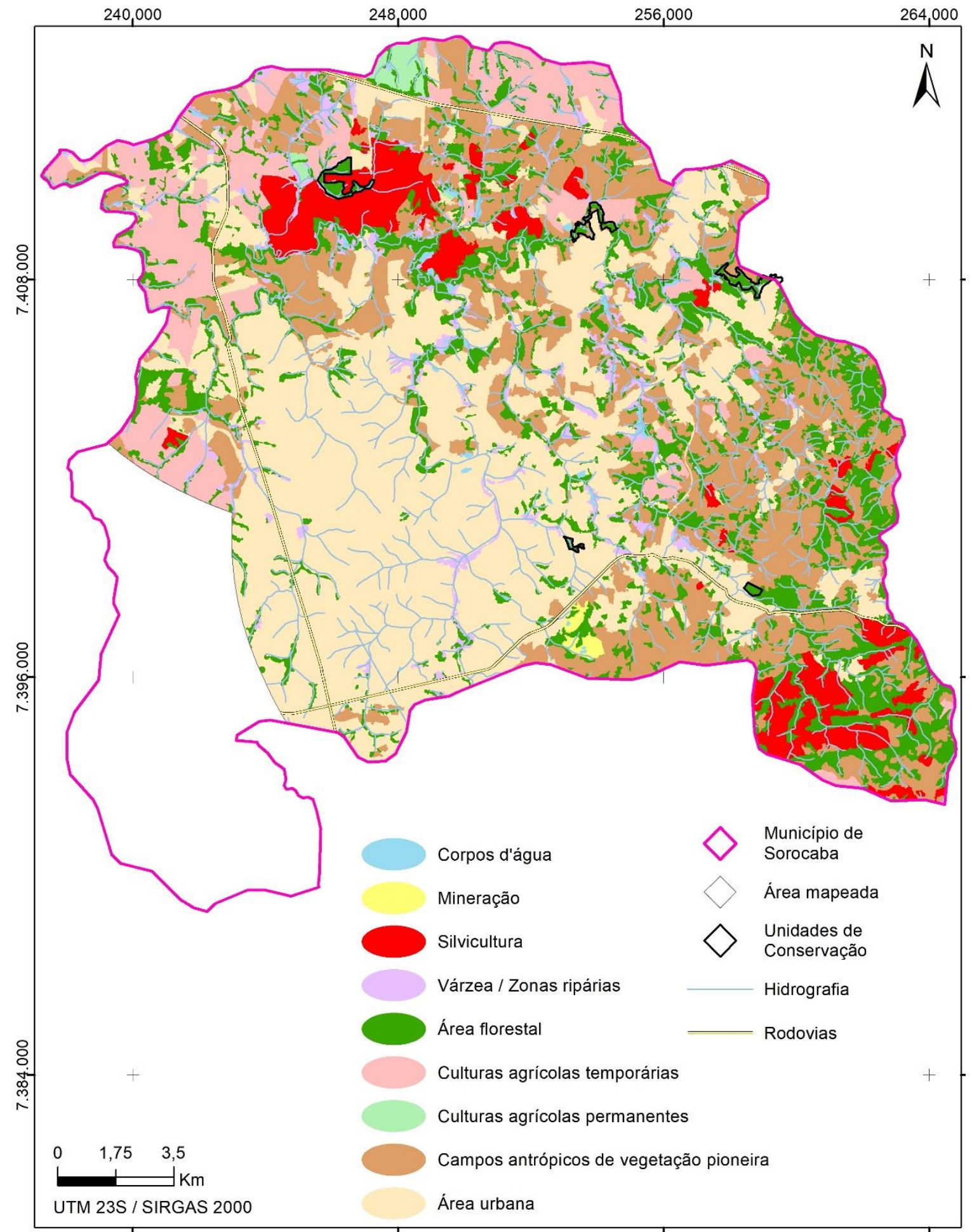

Figura 2: Úso e cobertura da terra da área mapeada no entorno das Unidades de Conservação do município de Sorocaba, estado de São Paulo, Brasil.

Figure 2: Land use/land cover of the mapped surrounding the Protected Areas in the city of Sorocaba, state of São Paulo, Brazil.

Fonte: CETESB (1977); CNUC (2012); DNIT (2013); Ribeiro; Mello e Valente (2020), adaptado pelas autoras (2021).

Source: CETESB (1977); CNUC (2012); DNIT (2013); Ribeiro; Mello e Valente (2020), adapted by the author (2021). 
Visto que a maioria das aves de florestas não consegue atravessar 100 metros de áreas abertas (SEKERCIOGLU, 2009) e a capacidade média de cruzamento de vazios é de apenas $150 \mathrm{~m}$ para espécies especializadas em florestas (HATFIELD; ORME; BANKS-LEITE, 2018), o diagnóstico de distância média entre UCs traz a importância da conservação de fragmentos florestais fora de áreas protegidas, com foco na manutenção da conectividade para a biodiversidade. Laurance et al. (2012) avaliam que as UCs tropicais, apesar de serem a base dos esforços no combate ao declínio da biodiversidade, não serão efetivas sem que estejam conectadas a outras UCs ou demais fragmentos da paisagem, reconhecendo que áreas tropicais protegidas estão ligadas ecologicamente aos seus habitats circundantes (GIBSON et al., 2011).

Observa-se que os fragmentos presentes dentro das UCs municipais fazem ligações com maciços contínuos da paisagem do entorno que estão sem proteção. Assim, as ações de incentivo da conservação de vegetação nativa em propriedades particulares são necessárias para garantir a manutenção das florestas urbanas (CROUZEILLES; LORINI; GRELLE, 2013; GUZMÁN WOLFHARD; RAEDIG, 2019). O reconhecimento apropriado dessas importantes áreas oferece a oportunidade de envolver e apoiar os detentores de direitos (proprietários particulares) e as partes interessadas e promover parcerias equitativas de esforços de conservação (IUCN, 2019b).

A área mapeada localizada no entorno das UCs do município de Sorocaba (Figura 2) é composta por áreas urbanas (39,47\%), campos antrópicos de vegetação pioneira $(23,48 \%)$, área florestal $(17,71 \%)$, culturas agrícolas temporárias $(8,61 \%)$, silvicultura $(6,17 \%)$, várzea e zonas ripárias $(3,07 \%)$, culturas agrícolas permanentes $(0,53 \%)$, corpos d'água $(0,73 \%)$ e áreas de mineração $(0,23 \%)$. O uso antrópico do uso da terra corresponde a mais de $78 \%$ da área mapeada, onde impera a área urbana. No século urbano (ELMQVIST et al., 2019), e seguindo uma tendência mundial, o espaço urbano do município de Sorocaba cresce acompanhando o crescimento econômico e o crescimento das populações urbanas (GRIMM et al., 2008; MARTINES; TOPPA; DE OLIVEIRA, 2015; SMITH et al., 2018).

Com relação à estrutura da cobertura florestal, obteve-se um total de 706 remanescentes florestais, os quais estão distribuídos no entorno das UCs municipais (Figura 3). Esses remanescentes possuem área variando entre 0,010 ha e 901,78 ha, com tamanho médio de 9,97 ha (desvio padrão $=44,51$ ha; coeficiente de variação $=446,59 \%$ ).

Dentre os 706 fragmentos, apenas $19(2,69 \%)$ apresentaram AREA > 50 ha, sendo que apenas um possui AREA $>500$ ha, evidenciando a predominância de pequenos fragmentos na paisagem. São $84,14 \%$ dos fragmentos com AREA < 10 ha, representam apenas $20,82 \%$ da área florestal da paisagem. Em uma paisagem antrópica como a da área de estudo, os pequenos remanescentes se tornam essenciais para a redução do isolamento dos fragmentos florestais na paisagem e para a manutenção da biodiversidade, servindo como trampolins ecológicos entre as grandes áreas florestais, sendo áreas protegidas ou não (RIBEIRO et al., 2009; ENEDINO; LOURES-RIBEIRO; SANTOS, 2018; REZENDE et al., 2018). 


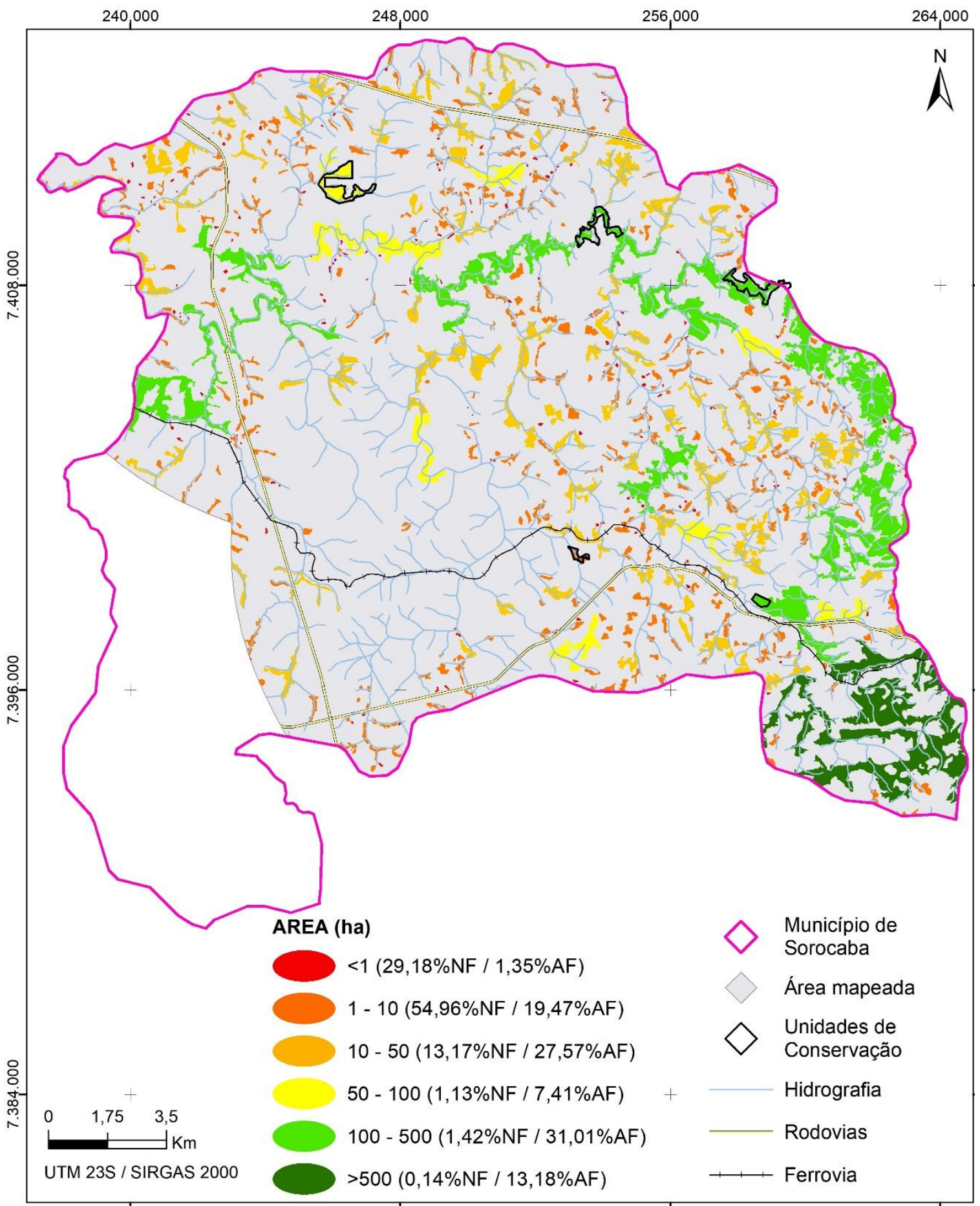

Figura 3: Distribuição dos remanescentes de floresta nativa, considerando classes de tamanho para área mapeada no entorno das Unidades de Conservação do município de Sorocaba, estado de São Paulo, Brasil. Número de remanescentes de floresta nativa (\%NF) e porcentagem da área (\%AF).

Figure 3: Distribution of native forest remnants considering size classes of the mapped surrounding the Protected Areas in the city of Sorocaba, state of São Paulo, Brazil. Number of native forest remnants (\%NF) and percentage of area (\%AF).

Fonte: CETESB (1977); CNUC (2012); DNIT (2013); Ribeiro; Mello e Valente (2020), adaptado pelas autoras (2021).

Source: CETESB (1977); CNUC (2012); DNIT (2013); Ribeiro; Mello e Valente (2020), adapted by the author (2021). 
A região leste, a mais declivosa da área de estudo, explica a presença do maior remanescente da paisagem, uma vez que seu relevo dificulta a expansão urbana e agrícola (MELLO; TOPPA; CARDOSO-LEITE, 2016). Com 901,78 ha esse remanescente está conectado a Estação Ecológica Bráulio Guedes da Silva e protege uma grande concentração de nascentes e riachos da zona leste, os quais formam o Rio Pirajibu (RIBEIRO; MELLO; VALENTE, 2020). Os remanescentes maiores são de grande importância para a manutenção da biodiversidade e devem ser foco de projetos de conservação, pois, além de apresentarem maior estabilidade contra variações ambientais, oferecem melhores perspectivas de sustentar espécies em longo prazo, como uma maior variedade de recursos alimentares e condições adequadas para reprodução, dispersão e sobrevivência (SEKERCIOGLU et al., 2002; RIBEIRO et al., 2009).

Avaliando a proximidade entre os remanescentes, observa-se que a maior parte dos fragmentos da paisagem $(54,47 \%$ do total) possui pelo menos um remanescente com proximidade mínima de $50 \mathrm{~m}$ de distância de outro (Figura 4), o que potencializa a dispersão das espécies nativas pela paisagem (ENEDINO; LOURES-RIBEIRO; SANTOS, 2018). O valor médio de proximidade foi de $83,61 \mathrm{~m}$ (desvio padrão $=115,01 \mathrm{~m}$; coeficiente de variação $=137,56 \%$ ) entre fragmentos florestais. Nesse contexto de urbanização em larga escala, o espaço antrópico significa uma barreira à migração natural de espécies naturais. Neste sentido, a melhoria da permeabilidade das paisagens urbanas pode ser conquistada através de trampolins ecológicos (HAN; KEEFFE, 2019) sendo a proximidade entre os remanescentes essencial para garantir a conservação da biodiversidade em ambientes antropizados (MARTENSEN; PIMENTEL; METZGER, 2008).

Observa-se que a Estação Ecológica Bráulio Guedes da Silva, a menor UC do município (8,9 ha) é a única que não tem o suporte de um remanescente fora dos limites protegidos. Essa UC deve estar sendo constantemente monitorada visto que a conservação depende não apenas da proteção, mas também da conexão com demais fragmentos da paisagem e com outras UCs (LOVEJOY; WILSON, 2015). A Estação Ecológica Bráulio Guedes da Silva está a aproximadamente $220 \mathrm{~m}$ do remanescente mais próximo. Além de não ter fragmentos muito próximos, essa UC está localizada a 4.965,40 m da UC mais próxima, que é o Parque Natural Municipal de Brigadeiro Tobias. Hatfield, Orme e Banks-Leite (2018) advertem, sobre UCs, em particular no Bioma da Mata Atlântica, estarem reduzida a fragmentos isolados, rodeados por áreas urbanas ou paisagens agrícolas, tornando-as totalmente insustentáveis e vulneráveis à extinção. 


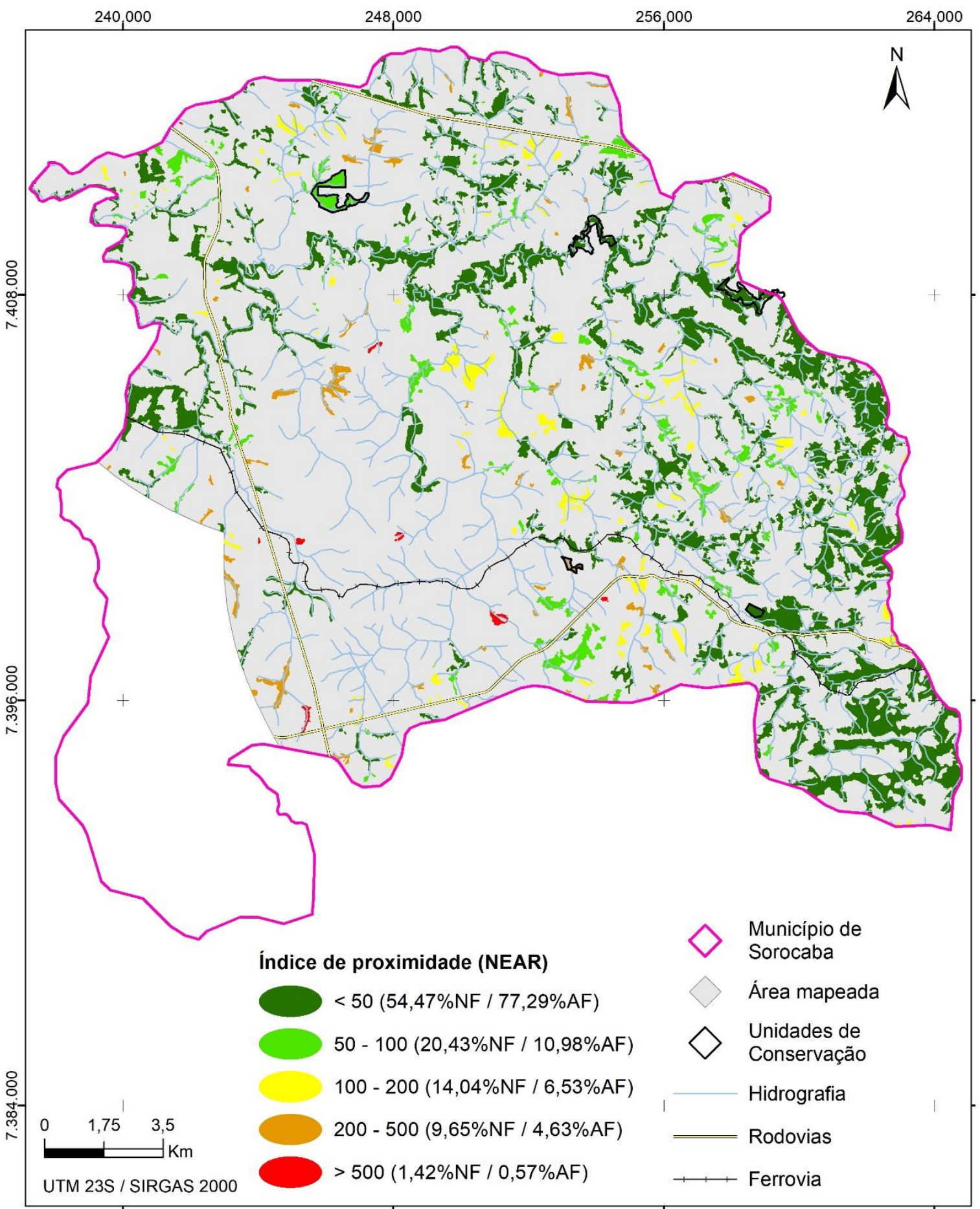

Figura 4: Distribuição dos remanescentes de floresta nativa, considerando as classes de índice NEAR para área mapeada no entorno das Unidades de Conservação do município de Sorocaba, estado de São Paulo, Brasil. Número de remanescentes de floresta nativa (\%NF) e porcentagem da área $(\% A F)$.

Figure 4: Distribution of native forest remnants considering NEAR index of the mapped surrounding the Protected Areas in the city of Sorocaba, state of São Paulo, Brazil. Number of native forest remnants (\%NF) and percentage of area (\%AF).

Fonte: CETESB (1977); CNUC (2012); DNIT (2013); Ribeiro; Mello e Valente (2020), adaptado pelas autoras (2021).

Source: CETESB (1977); CNUC (2012); DNIT (2013); Ribeiro; Mello e Valente (2020), adapted by the author (2021). 
Os campos antrópicos, que representam $23,48 \%$ da paisagem (Figura 5), são áreas não exploradas produtivamente, que podem ser considerados adequados para projetos de restauração florestal, principalmente em paisagens tropicais como a Mata Atlântica (LATAWIEC et al., 2015, 2016).

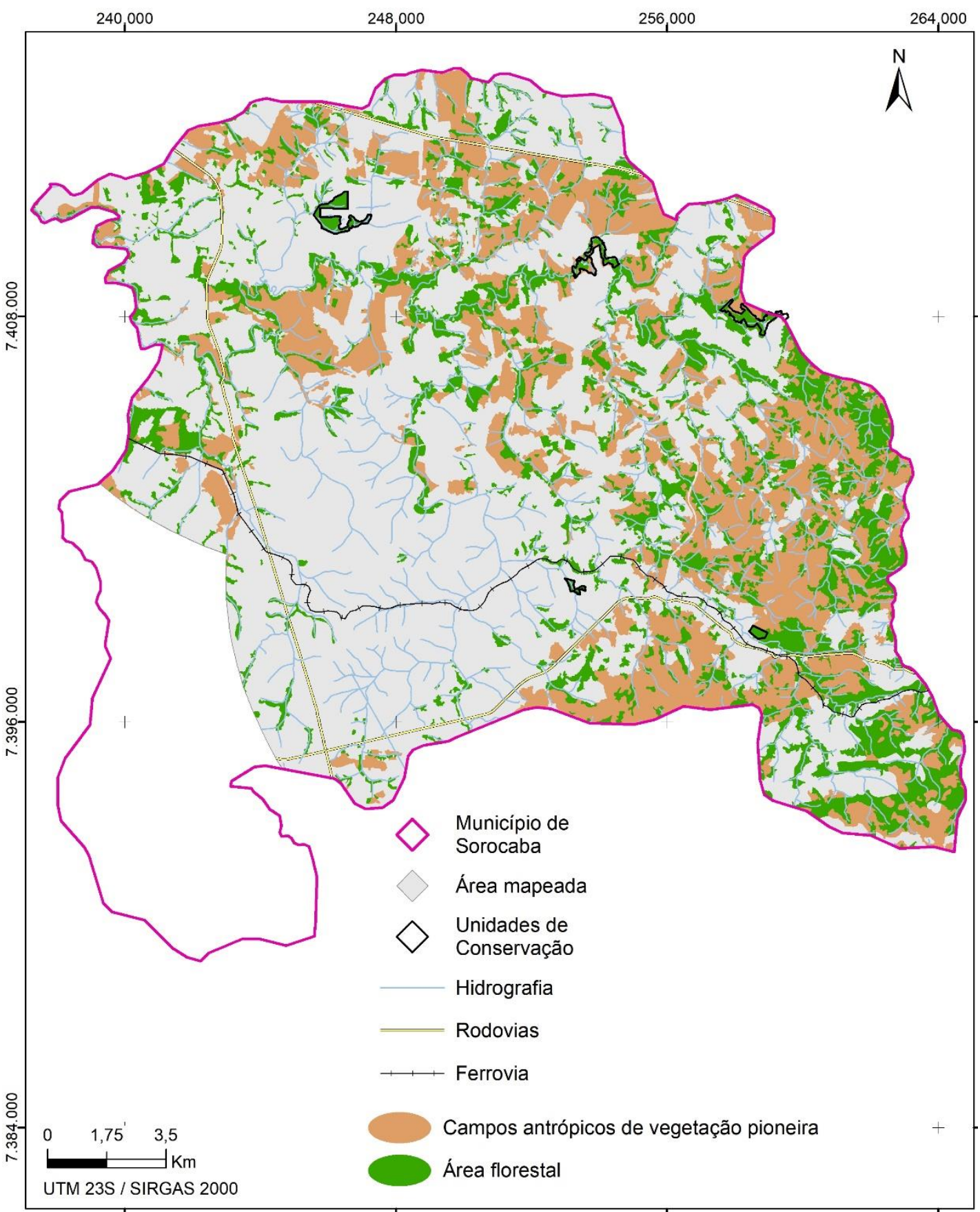

Figura 5: Distribuição dos remanescentes de floresta nativa e as áreas de campos antrópicos de vegetação pioneira para área mapeada no entorno das Unidades de Conservação do município de Sorocaba, estado de São Paulo, Brasil.

Figure 5: Native Forest remnants and Anthropic fields of the mapped surrounding the Protected Areas in the city of Sorocaba, state of São Paulo, Brazil.

Fonte: CETESB (1977); CNUC (2012); DNIT (2013); Ribeiro; Mello e Valente (2020), adaptado pelas autoras (2021).

Source: CETESB (1977); CNUC (2012); DNIT (2013); Ribeiro; Mello e Valente (2020), adapted by the author (2021). 
Estudos recentes, tal como o de Rezende et al. (2018), apontaram um crescimento das áreas em regeneração na Mata Atlântica, fenômeno relacionado à regeneração de vegetação nativa em campos degradados. Uma vez que as áreas urbanas são áreas consolidadas e dificilmente serão convertidas, os campos antrópicos presentes na paisagem urbana, como no caso da área de estudo, são áreas importantes para projetos de restauração florestal (RIBEIRO; MELLO; VALENTE, 2020). Contudo, a viabilidade de projetos de restauração, especialmente aqueles em áreas urbanas, depende do quão bem sucedidos socialmente eles são em obter aceitação pública (GOBSTER, 2010), que está relacionada a amplos objetivos de sustentabilidade, desde a proteção da biodiversidade até a melhoria da qualidade de vida da população urbana (TRZYNA, 2014; JAHANI; KALANTARY; ALITAVOLI, 2021).

Assim, na identificação das áreas de campos antrópicos presentes na paisagem observa-se que muitos estão envolvendo os remanescentes (Figura 5). Na Mata Atlântica, o abandono das terras, identificadas como campos antrópicos, ocorre principalmente em regiões próximas a rios e córregos, manchas de floresta e em encostas mais íngremes (MOLIN et al., 2017). A regeneração natural é uma forma promissora de recuperação dessas terras degradadas em paisagem urbana, e deve sempre ser considerada como uma alternativa de restauração paisagística (LATAWIEC et al., 2016), principalmente se tratando de custo. Segundo Crouzeilles et al. (2020) o planejamento da regeneração natural é a chave para obter uma restauração econômica em grande escala. A restauração florestal pode desempenhar um papel importante na mitigação dos impactos da fragmentação florestal (LEITE et al., 2013), melhorando a estrutura florestal e a conectividade da paisagem, promovendo a conexão entre as áreas protegidas e outros fragmentos florestais (DE MATOS et al., 2019).

\section{Considerações Finais}

A discussão e projetos de desenvolvimento de ZA em áreas urbanas é considerado um grande desafio. O SNUC determina que as UCs devem ser cercadas por zonas de amortecimento, onde a atividade humana é restrita, contudo, o tamanho estabelecido da reserva é arbitrário. Face a essa realidade, na delimitação da ZA deve levar em consideração critérios técnico-científicos, sobretudo de uso e ocupação da terra urbana.

No município de Sorocaba os entornos das áreas protegidas urbanas são compostos majoritariamente pelo uso antrópico da terra, que corresponde a mais de $78 \%$ da área mapeada, sendo a maior parte ocupada por áreas urbanas e campos antrópicos de vegetação pioneira.

A distância euclidiana média entre as UCs de Sorocaba é de 4.782,24 m. As UCs mais próximas são a Estação Ecológica Municipal do Pirajibu e a Estação Ecológica Governador Mário Covas e a UC mais isolada de outras UCs é o Parque Natural Municipal de Corredores da Biodiversidade. A Estação Ecológica Bráulio Guedes da Silva, a menor UC do município (8,9 ha) é a única que não tem o suporte de um remanescente fora dos limites protegidos.

A cobertura florestal nativa, nos entornos das áreas protegidas urbanas, está distribuída entre 706 remanescentes, sendo que $84,14 \%$ não possuem mais 
que dez (10) hectares. Apenas um fragmento tem mais de 500 ha e está localizado na zona leste da área de estudo, a região mais declivosa e com a maior concentração de nascentes e riachos. Apesar de pequenos, os remanescentes estão próximos entre si (NEAR < 50m), favorecendo dessa forma a conectividade, conquistada através de trampolins ecológicos.

Os campos antrópicos de vegetação pioneira apontados na área de estudo podem servir a projetos de restauração florestal, desempenhando um papel importante na mitigação dos impactos da fragmentação florestal, melhorando a estrutura florestal e a conectividade da paisagem, promovendo a conexão entre as áreas protegidas urbanas e outros fragmentos florestais. Assim, a restauração dos campos antrópicos pode ajudar a estabelecer um ambiente urbano ecologicamente sustentável, ajudando a trazer resiliência para a biodiversidade e, consequentemente, o provimento de serviços ecossistêmicos para toda a população.

É importante ainda ressaltar que em todo o globo a natureza está sendo pressionada e as pessoas estão perdendo o contato com ela, se deslocando cada dia mais para os centros urbanos. A desenfreada urbanização trouxe intenso detrimento para 0 meio ambiente e, consequentemente, para as pessoas. Assim, os esforços de conservação e preservação da vida humana nas cidades estão ancorados nas áreas protegidas urbanas e suas zonas circundantes, que são tão importantes quanto elas.

\section{Referências}

BRASIL. Lei no 9.985, de 18 de julho de 2000, 2000. Disponível em: $<$ http://www.planalto.gov.br/ccivil 03/leis/19985.htm>. Acesso em: 5 jul. 2021

CETESB. Enquadramento dos Corpos Hídricos - Arquivos digitais - Águas Interiores - Companhia Ambiental do Estado de São Paulo (Cetesb). Disponível em: <https://cetesb.sp.gov.br/aguas-interiores/enquadramento-doscorpos-hidricos-arquivos-digitais/>. Acesso em: 6 apr. 2019.

CNUC. Cadastro Nacional de Unidades de Conservação (CNUC). Disponível

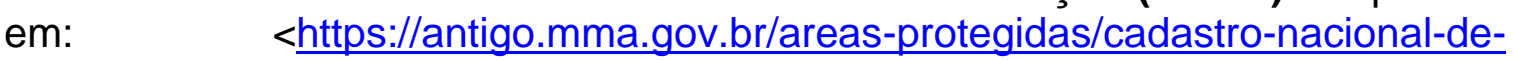
ucs/itemlist/category/130-cadastro-nacional-de-uc-s.html>. Acesso em: 14 sep. 2021.

CROUZEILLES, R.; LORINI, M. L.; GRELLE, C. E. V. The importance of using sustainable use protected areas for functional connectivity. Biological Conservation, v. 159, p. 450-457, Mar. 2013.

CROUZEILLES, R. et al. Achieving cost-effective landscape-scale forest restoration through targeted natural regeneration. Conservation letters, 18 Fev. 2020.

DE MATOS, T. P. V. et al. Protected areas and forest fragmentation: sustainability index for prioritizing fragments for landscape restoration. Geology, Ecology, and Landscapes, p. 1-13, 3 Dez. 2019.

DíAZ, S. et al. Biodiversity loss threatens human well-being. PLoS Biology, v. 4, n. 8, p. e277, 15 Ago. 2006. 


\section{DNIT. DEPARTAMENTO NACIONAL DE INFRAESTRUTURA DE} TRANSPORTES- DNIT. Disponível em: <http://www.dnit.gov.br/mapasmultimodais/shapefiles>. Acesso em: 3 sep. 2018.

ELMQVIST, T. et al. Sustainability and resilience for transformation in the urban century. Nature Sustainability, v. 2, n. 4, p. 267-273, Abr. 2019.

EMPLASA. EMPLASA - Empresa Paulista de Planejamento Metropolitano. Disponível em: <https://www.emplasa.sp.gov.br/>. Acesso em: 9 ago. 2018.

ENEDINO, T. R.; LOURES-RIBEIRO, A.; SANTOS, B. A. Protecting biodiversity in urbanizing regions: The role of urban reserves for the conservation of Brazilian Atlantic Forest birds. Perspectives in Ecology and Conservation, v. 16, n. 1, p. 17-23, Jan. 2018.

FAHRIG, L. Relative effects of habitat loss and fragmentation on population extinction. The Journal of Wildlife Management, v. 61, n. 3, p. 603, Jul. 1997.

FARINA, F. C. Abordagem sobre as técnicas de geoprocessamento aplicadas ao planejamento e gestão urbana. Cadernos EBAPE.BR, v. 4, n. 4, p. 01-13, Dec. 2006.

GIBSON, L. et al. Primary forests are irreplaceable for sustaining tropical biodiversity. Nature, v. 478, n. 7369, p. 378-381, Out. 2011.

GOBSTER, P. H. Urban Ecological Restoration. Nature and Culture, v. 5, n. 3, p. 227-230, 1 Dez. 2010.

GRIMM, N. B. et al. Global change and the ecology of cities. Science, v. 319, n. 5864, p. 756-760, 8 Fev. 2008.

GUZMÁN WOLFHARD, L. V.; RAEDIG, C. Connectivity conservation management: linking private protected areas. In: NEHREN, U. et al. (Eds.). Strategies and Tools for a Sustainable Rural Rio de Janeiro. Springer series on environmental management. Cham: Springer International Publishing, 2019. p. $155-171$.

HANSEN, A. J.; DEFRIES, R. Ecological mechanisms linking protected areas to surrounding lands. Ecological Applications, v. 17, n. 4, p. 974-988, Jun. 2007.

HANSKI, I. Habitat loss, the dynamics of biodiversity, and a perspective on conservation. Ambio, v. 40, n. 3, p. 248-255, Mai 2011.

HAN, Q.; KEEFFE, G. Stepping stones: Assessing the permeability of urban greenspaces to climate-driven migration of trees. Smart and Sustainable Built Environment, 11 Jun. 2019.

HATFIELD, J. H.; ORME, C. D. L.; BANKS-LEITE, C. Using functional connectivity to predict potential meta-population sizes in the Brazilian Atlantic Forest. Perspectives in Ecology and Conservation, v. 16, n. 4, p. 215-220, Out. 2018.

HILTY, J. et al. Guidelines for conserving connectivity through ecological networks and corridors. Gland, Switzerland: IUCN, International Union for Conservation of Nature, 2020.

IBGE. Malha Municipal - IBGE, 2019. Disponível em: $<$ https://www.ibge.gov.br/geociencias/organizacao-do-territorio/15774malhas.html?=\&t=0-que-e >. Acesso em: 23 feb. 2021. 
IBGE. Instituto Brasileiro de Geografia e Estatística (IBGE), 2020. Página inicial. Disponível em: <https://www.ibge.gov.br/>. Acesso em: 17 feb. 2021.

IUCN. Biodiversity and protected areas | IUCN, 2019a. Disponível em: $<$ https://www.iucn.org/commissions/world-commission-protected-areas/ourwork/biodiversity-and-protected-areas >. Acesso em: 6 abr. 2019.

IUCN. Recognising and reporting other effective area-based conservation measures | IUCN Library System, 2019b. Disponível em: $<$ https://doi.org/10.2305/IUCN.CH.2019.PATRS.3.en>. Acesso em: 21 jul. 2020.

JAHANI, A.; KALANTARY, S.; ALITAVOLI, A. An application of artificial intelligence techniques in prediction of birds soundscape impact on tourists' mental restoration in natural urban areas. Urban Forestry \& Urban Greening, v. 61, p. 127088, Jun. 2021.

JENKINS, C. N.; JOPPA, L. Expansion of the global terrestrial protected area system. Biological Conservation, v. 142, n. 10, p. 2166-2174, Out. 2009.

JOLY, C. A.; METZGER, J. P.; TABARELLI, M. Experiences from the Brazilian Atlantic Forest: ecological findings and conservation initiatives. The New Phytologist, v. 204, n. 3, p. 459-473, Nov. 2014.

LATAWIEC, A. E. et al. Creating space for large-scale restoration in tropical agricultural landscapes. Frontiers in Ecology and the Environment, v. 13, n. 4, p. 211-218, Mai 2015.

LATAWIEC, A. E. et al. Natural regeneration and biodiversity: a global metaanalysis and implications for spatial planning. Biotropica, v. 48, n. 6, p. 844-855, Nov. 2016.

LAURANCE, W. F. et al. Averting biodiversity collapse in tropical forest protected areas. Nature, v. 489, n. 7415, p. 290-294, 13 Set. 2012.

LEITE, M. DE S. et al. Landscape ecology perspective in restoration projects for biodiversity conservation: a review. Natureza \& Conservação, v. 11, n. 2, p. 108-118, 2013.

LOVEJOY, T. E.; WILSON, E. O. The Opinion Pages: A Mojave Solar Project in the Bighorns Way. The New York Times, v. 12, 2015.

LOVELL, S. T.; TAYLOR, J. R. Supplying urban ecosystem services through multifunctional green infrastructure in the United States. Landscape Ecology, v. 28, n. 8, p. 1447-1463, Out. 2013.

MARTENSEN, A. C.; PIMENTEL, R. G.; METZGER, J. P. Relative effects of fragment size and connectivity on bird community in the Atlantic Rain Forest: Implications for conservation. Biological Conservation, v. 141, n. 9, p. 21842192, Set. 2008.

MARTINES, M. R.; TOPPA, R. H.; DE OLIVEIRA, P. S. S. Expansão da mancha urbana de Sorocaba, São Paulo, no período de 2002 a 2009: subsídios ao Plano Diretor por meio de técnicas de Geoprocessamento. Anais XVII Simpósio Brasileiro de Sensoriamento Remoto, 25 Abr. 2015.

MCGARIGAL, K. FRAGSTATS help. Documentation for FRAGSTATS, v. 4, 2015. 
MELLO, K. DE; TOPPA, R. H.; CARDOSO-LEITE, E. Priority areas for forest conservation in an urban landscape at the transition between atlantic forest and cerrado. CERNE, v. 22, n. 3, p. 277-288, Set. 2016.

METZGER, J. P. Como lidar com regras pouco óbvias para conservação da biodiversidade em paisagens fragmentadas. Natureza \& Conservação, v. 4, n. 2, p. 11-23, 1 Out. 2006.

MOLIN, P. G. et al. Spatial determinants of Atlantic Forest loss and recovery in Brazil. Landscape Ecology, v. 32, n. 4, p. 857-870, Abr. 2017.

OPDAM, P.; STEINGRÖVER, E.; ROOIJ, S. VAN. Ecological networks: A spatial concept for multi-actor planning of sustainable landscapes. Landscape and Urban Planning, v. 75, n. 3-4, p. 322-332, Mar. 2006.

PICHARILLO, C.; RANIERI, V. E. L. Payment for environmental services: guidelines for identifying priority areas focusing on biodiversity*. Ambiente \& sociedade, v. 22, 2019.

REZENDE, C. L. et al. From hotspot to hopespot: An opportunity for the Brazilian Atlantic Forest. Perspectives in Ecology and Conservation, Out. 2018.

RIBEIRO, M. C. et al. The Brazilian Atlantic Forest: How much is left, and how is the remaining forest distributed? Implications for conservation. Biological Conservation, v. 142, n. 6, p. 1141-1153, Jun. 2009.

RIBEIRO, M. P.; MELLO, K. D.; VALENTE, R. A. Avaliação da estrutura da paisagem visando à conservação da biodiversidade em paisagem urbanizada. Ciência Florestal, v. 30, n. 3, p. 819-834, 1 Sep. 2020.

RIBEIRO, M. P.; MELLO, K. DE; VALENTE, R. A. Caminhos de conectividade no espaço urbano. Anais. I Congresso Latino-Americano de Desenvolvimento Sustentável. ANAP, 2021

SANTINI, L.; SAURA, S.; RONDININI, C. Connectivity of the global network of protected areas. Diversity and Distributions, v. 22, n. 2, p. 199-211, Fev. 2016.

SAURA, S. et al. Protected area connectivity: Shortfalls in global targets and country-level priorities. Biological conservation, v. 219, p. 53-67, Mar. 2018.

SAYER, J. Rainforest buffer zones: guidelines for protected area managers. [s.I.] International Union for Conservation of Nature and Natural Resources, 1991.

SEKERCIOGLU, C. H. et al. Disappearance of insectivorous birds from tropical forest fragments. Proceedings of the National Academy of Sciences of the United States of America, v. 99, n. 1, p. 263-267, 8 Jan. 2002.

SEKERCIOGLU, C. H. Tropical ecology: riparian corridors connect fragmented forest bird populations. Current Biology, v. 19, n. 5, p. R210-3, 10 Mar. 2009.

SHANAHAN, D. F. et al. The Health Benefits of Urban Nature: How Much Do We Need? Bioscience, v. 65, n. 5, p. 476-485, 1 Mai 2015.

SMITH, W. S. et al. Urban biodiversity: how the city can do its management?

Biodiversity International Journal, v. 2, n. 2, p. 246-251, 11 Mai 2018. 
SOROCABA. Decreto No 19.424, de 17 De Agosto De 2011. Cria o Parque Natural Municipal Corredores de Biodiversidade a dá outras providências, 2011. Disponível em: $<$ https://leismunicipais.com.br/a/sp/s/sorocaba/decreto/2011/1942/19424/decreto -n-19424-2011-cria-o-parque-natural-municipal-corredores-de-biodiversidade-eda-outras-providencias>. Acesso em: 5 jan. 2019.

SOROCABA. LEI No 10.240, de 29 de agosto de 2012. Dispõe sobre s criação do Conselho do Parque Natural Municipal Corredores de Biodiversidade CPNMCBIO, e dá outras providências, 2012. Disponível em: $<$ https://leismunicipais.com.br/a1/sp/s/sorocaba/leiordinaria/2012/1024/10240/lei-ordinaria-n-10240-2012-dispoe-sobre-a-criacaodo-conselho-do-parque-natural-municipal-corredores-de-biodiversidadecpnmcbio-e-da-outras-providencias >. Acesso em: 5 jan. 2021.

SOROCABA. plano Municipal de Conservação e Recuperação da Mata Atlântica (P. M. de Sorocaba, Ed.). Sorocaba: Prefeitura Municipal de Sorocaba, 1 Fev. 2014.

SOROCABA. Decreto $n^{\circ} 21.618$, de 7 de janeiro de 2015. cria o Parque Natural Municipal de Brigadeiro Tobias e dá outras providências, 2015a. Disponível em: $<$ https://leismunicipais.com.br/a/sp/s/sorocaba/decreto/2015/2162/21618/decreto -n-21618-2015-cria-o-parque-natural-municipal-de-brigadeiro-tobias-e-da-outrasprovidencias-2015-09-16-versao-compilada>. Acesso em: 6 jan. 2019a.

SOROCABA. Decreto $\mathbf{n}^{\circ} \mathbf{2 2 . 0 2 3}$, de 28 de outubro de 2015. Cria a Estação Ecológica Municipal do Piragibú e dá outras providências, 2015b. Disponível em: $<$ https://leismunicipais.com.br/a/sp/s/sorocaba/decreto/2015/2203/22023/decreto -n-22023-2015-cria-a-estacao-ecologica-municipal-do-piragibu-e-da-outrasprovidencias $>$. Acesso em: 8 jan. 2019b.

SOROCABA. Lei $\mathbf{n}^{\circ} \mathbf{1 1 . 2 3 4}$, de 10 de dezembro de 2015. Cria a Estação Ecológica "Governador Mário Covas", revoga expressamente a lei n 6.416, de 22 de junho de 2001, que cria o Parque Municipal "Governador Mário Covas" e dá outras providências, 2015c. Disponível em: $<$ https://leismunicipais.com.br/a/sp/s/sorocaba/lei-ordinaria/2015/1123/11234/leiordinaria-n-11234-2015-cria-a-estacao-ecologica-governador-mario-covasrevoga-expressamente-a-lei-n-6416-de-22-de-junho-de-2001-que-cria-o-parquemunicipal-governador-mario-covas-e-da-outras-providencias >. Acesso em: 6 jan. 2019c.

SOROCABA. Lei No 11.471, de 20 de dezembro de 2016. Cria a Estação Ecológica "Bráulio Guedes da Silva", revoga expressamente a Lei n 4.043, de 19 de outubro de 1992, que cria o Parque Natural "Bráulio Guedes da Silva", e dá outras providências, 2016. Disponível em: $<$ https://leismunicipais.com.br/a/sp/s/sorocaba/lei-ordinaria/2016/1148/11471/leiordinaria-n-11471-2016-cria-a-estacao-ecologica-braulio-guedes-da-silvarevoga-expressamente-a-lei-n-4043-de-19-de-outubro-de-1992-que-cria-oparque-natural-braulio-guedes-da-silva-e-da-outras-providencias>. Acesso em: 8 jan. 2019. 
TEEB. The Economics of Ecosystems and Biodiversity: Mainstreaming the Economics of Nature: A Synthesis of the Approach, Conclusions and Recommendations of TEEB. Disponível em: $<$ http://www.teebweb.org/publication/mainstreaming-the-economics-of-nature-asynthesis-of-the-approach-conclusions-and-recommendations-of-teeb/>. Acesso em: 7 ago. 2020.

TRZYNA, T. (ED.). Urban Protected Areas: Profiles and best practice guidelines. xiv. ed. Gland, Switzerland: IUCN, 2014. p. 110

UN; WHO (EDS.). Integrating health in urban and territorial planning: a sourcebook. Geneva: UN-Habitat and World Health Organization, 2020.

\section{Agradecimentos}

O presente trabalho foi realizado com apoio da Coordenação de Aperfeiçoamento de Pessoal de Nível Superior - Brasil (CAPES) - Código de Financiamento 001 (Processo: 88887.603853/2021-00) e do Programa de Pósgraduação em Planejamento e Uso de Recursos Renováveis da Universidade Federal de São Carlos (UFSCar), campus Sorocaba.

Kaline de Mello: Universidade Federal de São Carlos, Sorocaba, SP, Brasil.

E-mail: kaline.mello@usp.br

Link para curriculum lattes: http://lattes.cnpq.br/1974531968891537

Marina Pannunzio Ribeiro: Universidade Federal de São Carlos, Sorocaba, SP, Brasil.

E-mail: marinapr@estudante.ufscar.br

Link para curriculum lattes: $\underline{\text { http://lattes.cnpq.br/0358232596051980 }}$

Roberta Averna Valente: Universidade Federal de São Carlos, Sorocaba, SP, Brasil.

E-mail: roavalen@ufscar.br

Link para curriculum lattes: http://lattes.cnpq.br/1582627535733911 